\section{Saberes e práticas sobre controle do Aedes aegypti por diferentes sujeitos sociais na cidade de Salvador, Bahia, Brasil}

\author{
Knowledge and practices in Aedes aegypti control \\ among different social subjects in Salvador, Bahia \\ State, Brazil
}

\section{Conocimientos y prácticas sobre el control del Aedes aegypti realizado por diferentes sujetos sociales en la ciudad de Salvador, Bahía, Brasil}

\author{
Kathleen Ribeiro Souza 1 \\ Maria Lígia Rangel Santos 2 \\ Isabel Cristina Santos Guimarães 3 \\ Guilherme de Sousa Ribeiro 1,2 \\ Luciano Kalabric Silva 1
}

doi: 10.1590/0102-311X00078017

\section{Resumo}

Devido à persistência da dengue e de outras arboviroses no Brasil, o poder público tem intensificado as ações de combate ao mosquito vetor Aedes aegypti. Os agentes de combate às endemias (ACE) e agentes comunitários de saúde (ACS), dentre outras atribuições, tornaram-se interlocutores e disseminadores de conhecimento na comunidade. O objetivo deste trabalho foi analisar os saberes e práticas sobre controle da dengue por diferentes sujeitos sociais: moradores e agentes. Foram realizadas entrevistas com moradores, ACE de campo e de mobilização e ACS em dois bairros de Salvador, Bahia, por meio da metodologia de grupo focal. Os moradores demonstraram incerteza sobre a forma de contágio e o perigo da dengue. Os ACE de campo apresentam-se em conflito, pela necessidade de informar à comunidade sobre aspectos que não dominam e demonstram um descontentamento pessoal no trabalho com um sentimento de desvalorização pela falta de qualificação. Os ACE de mobilização culpam a população e enfatizam a importância de si próprios como solução para o controle da dengue. Os ACS não apropriaram sua experiência de campo em seu discurso e se sentem desobrigados com respeito ao controle vetorial. Todos os grupos entrevistados concordam que a culpa da dengue recai sobre o poder público, e a solução para o problema está na educação. Percebe-se uma grande necessidade de intervenções educativas regulares, pautadas no diálogo e na sensibilização para lidar com a realidade cotidiana dos moradores, trazendo os indivíduos (moradores e agentes) como sujeitos do processo de construção de conhecimento. Pois, na metodologia atual, a disseminação de informação e conhecimento não é suficiente para promover melhorias na comunidade para o controle da dengue.

Conhecimentos, Atitudes e Prática em Saúde; Controle de Doenças

Transmissíveis; Dengue
Correspondência

K. R. Souza

Laboratório de Patologia e Biologia Molecular, Instituto Gonçalo Moniz, Fundação Oswaldo Cruz.

Rua Waldemar Falcão 121, Salvador, BA 40296-710, Brasil. kathleen_ribeiro@yahoo.com.br

1 Instituto Gonçalo Moniz, Fundação Oswaldo Cruz, Salvador, Brasil.

2 Instituto de Saúde Coletiva, Universidade Federal da Bahia, Salvador, Brasil.

3 Centro de Controle de Zoonoses, Secretaria Municipal da Saúde, Salvador, Brasil. 


\section{Introdução}

A persistência da dengue e a recente introdução de outras arboviroses no Brasil, tais como a febre de Chikungunya e a febre do Zika, trazem ao país o desafio de combater, com eficiência, o mosquito vetor, o Aedes aegypti 1,2,3.

$\mathrm{O}$ aumento da incidência da dengue e de outras arboviroses em áreas urbanas está associado ao adensamento populacional, à urbanização desordenada, à intermitência da distribuição de água e ao transporte de pessoas e mercadorias, que facilitam a dispersão do vetor e dos vírus por todo o mundo $4,5,6,7$.

Com o agravamento da situação, o poder público tem intensificado as ações de controle vetorial já existentes em todo o país. Contudo, tais ações têm-se mostrado ineficazes na redução do índice de infestação predial (IIP) do A. aegypti e, por conseguinte, na diminuição da incidência das doenças por ele transmitidas 8,9 .

Apesar da existência de uma vacina para dengue, as opções de medidas de controle disponíveis ainda são restritas e têm, como objetivo, a redução dos índices de infestação por $A$. aegypti, realizada por programas de controle vetoriais que são caros e difíceis de manter 10. Dentre os componentes do Programa Nacional de Controle da Dengue (PNCD), estão o combate ao vetor e as ações integradas de educação em saúde, comunicação e mobilização social 11.

Com a implantação do PNCD, foi instituído o papel dos agentes de combate às endemias (ACE), que têm, por atribuições, o exercício de atividades de vigilância, prevenção e controle de doenças endêmicas e promoção da saúde 12,13. Em cada bairro do Município de Salvador, Bahia, parte dos ACE de campo compõe uma equipe responsável por ações de educação na comunidade, distinguindo-se como ACE de mobilização.

Instituído e regulamentado em 1997, o Programa de Agentes Comunitários de Saúde (PACS) teve como iniciativa buscar alternativas para melhorar as condições de saúde de suas comunidades, com a atuação do agente comunitário de saúde (ACS), que tem um conjunto de atribuições de cunho político e social ligadas à competência de promoção da saúde 14,15,16.

Por serem servidores municipais que trabalham em contato direto com a população, os agentes tornaram-se sujeitos de importância estratégica na promoção da saúde. Os ACS são o elo entre comunidade e serviços públicos de saúde, atuando como educadores ou disseminadores de conhecimento na comunidade 17.

A educação pode ser definida como a construção e o compartilhamento de conhecimentos em um processo dinâmico das interações sociais, por meio de linguagem ${ }^{18}$. Portanto, o trabalho de educação e comunicação se dá em meio a um sistema complexo de produção, circulação e apropriação de signos e significados públicos, que não estão alojados na mente das pessoas, mas nas relações/interações sociais 19 .

Esta pesquisa teve por objetivo analisar os saberes e as práticas de moradores, ACE e ACS sobre o controle da dengue em uma área populosa e vulnerável na cidade de Salvador, Bahia, Brasil. Esperase contribuir com um diagnóstico sobre linguagem, formas de percepção e ação dos sujeitos face à dengue, em uma região do Município de Salvador.

\section{Metodologia}

O estudo possui desenho descritivo de caráter exploratório, com uma abordagem qualitativa. A técnica de grupo focal (GF) permite observar as opiniões emitidas e percepções expressas pelos sujeitos participantes, produzindo dados que conduzam à interpretação e à compreensão da realidade estudada 20,21,22. A técnica utiliza-se do diálogo em grupo, podendo incluir de 6 a 12 pessoas, além de um moderador, um relator e um observador, para produzir dados acerca de um tema específico.

O estudo foi realizado em dois bairros na região do distrito sanitário do Subúrbio Ferroviário, no Município de Salvador: Periperi e Plataforma, pois apresentam IIP elevados (> 1\%) (dados do Centro de Controle de Zoonoses, Prefeitura Municipal de Salvador; Isolina Ciuffo, 2018, comunicação pessoal). 
Trata-se de um distrito formado por 22 bairros empobrecidos, em área de aproximadamente 4.145ha, com cerca de 500 mil habitantes, portanto, uma parte populosa da cidade. É habitado, em sua maioria, por pessoas privadas de um tratamento de políticas públicas de qualidade, com falta de infraestrutura urbana e de serviços 23 . Os bairros de Periperi e Plataforma são compostos por cerca de 16 mil imóveis cada um, que, em sua grande maioria, são casas com acesso em asfalto (dados do Centro de Controle de Zoonoses, Prefeitura Municipal de Salvador; Isolina Ciuffo, 2018, comunicação pessoal).

Foram convidados para participar deste estudo moradores, ACE de campo e de mobilização, e ACS de ambos os bairros. A seleção dos moradores foi realizada durante uma mobilização educativa, por meio de uma feira de saúde promovida dentro de cada bairro. Os moradores foram aleatoriamente convidados a participar do GF. Os indivíduos que aceitaram o convite foram encaminhados para espaços comunitários onde ocorreram as entrevistas.

Para os agentes, ACE de campo e mobilização e ACS, os convites foram feitos aleatoriamente pelo moderador da ação, que não conhecia os agentes, assim minimizando prováveis vieses de seleção. Para diminuir o nível de relação pessoal, dentro de cada grupo, foram incluídos membros das equipes dos dois bairros. Os encontros ocorreram em escolas municipais com os indivíduos que aceitaram participar.

Após esclarecimento sobre o estudo, todos os participantes assinaram um termo de autorização em substituição ao tradicional Termo de Consentimento Livre e Esclarecido (TCLE). As discussões duraram aproximadamente duas horas, de modo completamente flexível e não estruturadas. Entretanto, coube ao moderador redirecionar a discussão, caso houvesse dispersão, sem interromper bruscamente a interação do grupo, conforme recomendado na literatura 21,24.

Esta pesquisa foi submetida e aprovada pelo Comitê de Ética em Pesquisa do Instituto Gonçalo Moniz, Fundação Oswaldo Cruz, por meio do CAAE no 42940514.1.0000.0040 do Conselho Nacional de Saúde.

\section{Coleta de dados}

Os dados foram produzidos em 2014, referentes aos sete GF, incluindo dois de moradores, quatro de ACE (de campo e de mobilização) e um de ACS. Informações sobre aspectos sociais dos participantes foram coletadas, e seus nomes foram mantidos em sigilo. Os GF foram orientados por um guia com perguntas sobre concepções, causalidade e práticas de prevenção da dengue, incluído na Tabela 1, as conversas foram gravadas e, posteriormente, transcritas literalmente.

\section{Análise dos dados}

A partir da leitura dos depoimentos, foi realizada a indexação dos dados em categorias e conceituações de acordo com a Tabela 1. O software Nvivo, versão 10.0 (https://www.qsrinternational.com/), foi utilizado para facilitar a categorização e a interpretação dos dados 25 .

Tabela 1

Categorias de análise dos dados por afinidade de conceitos.

\begin{tabular}{lrl}
\hline Categorias & Conceituações & Perguntas realizadas \\
\hline Saberes/Concepções & Saberes/Conceitos sobre dengue & $\begin{array}{c}\text { O que sabe sobre dengue? O quê? Onde e quando (fonte e local de } \\
\text { informação)? No seu bairro, tem ou já teve dengue? Onde? }\end{array}$ \\
Saberes/Causalidade & Discursos sobre a causalidade da dengue & $\begin{array}{c}\text { O que causa/ou a dengue? E no seu bairro? Que tipos de locais } \\
\text { (criadouros) você relaciona com a presença do Aedes aegypti? }\end{array}$ \\
Prática de prevenção & O que deveria ser feito para evitar a dengue & O que você faz para evitar/prevenir a dengue? O que os outros \\
& & fazem para evitar/prevenir a dengue? O que você acha que deveria \\
& & ser feito para evitar/prevenir a dengue? E os outros?
\end{tabular}


Os dados foram analisados considerando-se as concepções/saberes sobre a dengue, sua causalidade e formas de prevenção na visão dos diferentes grupos abordados: moradores, ACE, ACE de mobilização e ACS.

\section{Resultados}

Ao todo, 56 indivíduos participaram do estudo compondo um total de sete GFs (Tabela 2). Para a realização das entrevistas, o grupo de ACE foi segregado, devido à grande quantidade de agentes que aceitaram participar do estudo.

Não houve diferença significativa entre os grupos, a idade dos participantes variou entre 19 e 71 anos, com predomínio de indivíduos do sexo feminino (75\%) e Ensino Médio completo (48,2\%) (Tabela 3).

Os resultados dos GF foram elucidados e organizados em categorias e conceituações por grupos entrevistados: moradores, ACE de campo, ACE de mobilização e ACS. Os conceitos-chave que surgem nos discursos dos sujeitos foram traduzidos/interpretados quanto a possíveis significados (o que o discurso denota) atribuídos a concepções, causalidade e práticas de prevenção da dengue em cada grupo. Os resultados foram resumidos na Tabela 4.

Tabela 2

Local, período e tipo de participantes dos grupos focais $(\mathrm{N}=56)$.

\begin{tabular}{lccc}
\hline Grupo & Data & Participantes & $\mathbf{n}$ \\
\hline 1 & 28 de março & ACE & 9 \\
2 & 2 de abril & ACE & 8 \\
3 & 4 de abril & ACE & 10 \\
4 & 11 de abril & ACE de mobilização & 5 \\
6 & 12 de junho & ACS & 7 \\
7 & 17 de junho & Comunidade de Plataforma & 8 \\
\hline
\end{tabular}

ACE: agentes de combate às endemias; ACS: agentes comunitários de saúde.

Tabela 3

Características dos participantes dos grupos focais $(N=56)$.

\begin{tabular}{lc} 
Características dos participantes & \\
\hline Sexo [n (\%)] & $42(75 \%)$ \\
$\quad$ Feminino & $14(25 \%)$ \\
$\quad$ Masculino & $19-71$ \\
Idade [mínino-máximo] & $5(9 \%)$ \\
Escolaridade [n (\%)] & $27(48 \%)$ \\
$\quad$ Ensino Fundamental & $24(43 \%)$ \\
$\quad$ Ensino Médio completo & $630,00-3.500,00$
\end{tabular}


Tabela 4

Conceitos-chave nos discursos dos sujeitos de pesquisa e possíveis significados.

\begin{tabular}{|c|c|c|}
\hline Sujeitos & Discurso & Significado \\
\hline $\begin{array}{l}\text { Moradores - incerteza, contágio } \\
\text { e perigo }\end{array}$ & $\begin{array}{l}\text { Saberes e concepções sobre dengue } \\
\text { - "É uma doença contagiosa, né? Porque é uma doença que } \\
\text { se espalha, né? Por este mundo todo, né? É muito perigosa" } \\
\text { "Quando ele sai do vasilhame, ele já está pronto para voar } \\
\text { e atacar qualquer um" } \\
\text { Causalidade da doença } \\
\text { - "Na verdade, eu acho assim. Se o foco da dengue } \\
\text { aumenta, é culpa do próprio povo, que não procura } \\
\text { preservar suas águas, manter tampada. Jogam cocos à toa" }\end{array}$ & $\begin{array}{l}\text { • Familiaridade com termos científicos sem } \\
\text { saber seu significado. } \\
\text { • Desconhecimento do ciclo de vida do vetor } \\
\text { Redução da causalidade da doença ao vetor. } \\
\text { • Ausência de consciência sobre a } \\
\text { multicausalidade da doença. } \\
\text { • Culpabilização da própria população. }\end{array}$ \\
\hline ACE de campo - sujeitos em conflito & $\begin{array}{c}\text { Saberes e concepções sobre dengue } \\
\text { - "Como é que a gente pode passar para o morador se a } \\
\text { gente não tem uma formação de como é" } \\
\text { Causalidade - insatisfação com o trabalho } \\
\text { "Mas, quando a gente termina o LIRAa, quando eles fazem } \\
\text { a análise e tudo, o índice nunca chega para a gente saber } \\
\text { se o nosso trabalho está sendo eficaz ou não. Não } \\
\text { tem resposta" }\end{array}$ & $\begin{array}{l}\text { • Consciência de conhecimento limitado e } \\
\text { inacessível. } \\
\text { - Não se insere como sujeito da comunidade, } \\
\text { por ser um agente. } \\
\text { • Visão tradicional da educação } \\
\text { • Sentimento de desvalorização e } \\
\text { esquecimento devido ao descaso do governo } \\
\text { para com essa classe de trabalhadores. }\end{array}$ \\
\hline $\begin{array}{l}\text { ACE de mobilização - ação coletiva } \\
\text { para evitar a dengue }\end{array}$ & $\begin{array}{c}\text { Prática ideal } \\
\text { • "A gente realiza várias ações também na área, sobre } \\
\text { essas questões, se alguém perguntar a gente tem um } \\
\text { embasamento total, e os colegas aqui agora mesmo } \\
\text { passaram informações bem interessantes, né? Participo de } \\
\text { mobilizações quando pode, eu sempre dou uma olhadinha, } \\
\text { uma lida para saber o que eu vou falar se alguém me } \\
\text { perguntar. Então é uma questão de multiplicar, né? Nós } \\
\text { estamos fazendo o que, multiplicando os conhecimentos" } \\
\text { • "Eu acho que as escolas poderiam começar a colocar } \\
\text { questionários e colocar para os alunos conhecimento. } \\
\text { Passar os órgãos de novo, e obrigar que as escolas fizessem } \\
\text { esse tipo de ação" }\end{array}$ & $\begin{array}{l}\text { • Apropriação do conhecimento. } \\
\text { • Disposição para informar e educar. } \\
\text { • Valorização do sujeito da ação de prevenção. } \\
\text { • Visão de ação coletiva. } \\
\text { • Visão de ação intersetorial no controle } \\
\text { da dengue. }\end{array}$ \\
\hline $\begin{array}{l}\text { ACS - dengue: complexidade } \\
\text { desconhecida }\end{array}$ & $\begin{array}{c}\text { Saberes e concepções } \\
\text { - "E apesar de muitos não se darem conta, é mais perigosa } \\
\text { do que muitos pensam, tanto é que se pode levar até à } \\
\text { morte. É uma doença, ela tem sintomas de virose. Ela pode } \\
\text { ser confundida com a virose, com a rubéola, e também" } \\
\text { Prática ideal } \\
\text { • "População tem que tomar mais consciência ainda, e } \\
\text { cuidar mais e sustentar esse ambiente" }\end{array}$ & $\begin{array}{c}\text { - Conhecimento da gravidade e complexidade. } \\
\text { - Não se sentem responsáveis pela solução do } \\
\text { problema da dengue. } \\
\text { • Visão da necessidade do envolvimento da } \\
\text { população no controle e talvez } \\
\text { da culpabilização. }\end{array}$ \\
\hline
\end{tabular}

ACE: agentes de combate às endemias; ACS: agentes comunitários de saúde.

\section{Saberes e práticas dos moradores}

As concepções dos moradores sobre a dengue se caracterizam pela incerteza sobre a forma de contágio e o perigo da doença. Nas entrevistas, foi possível observar que as pessoas mostram certa familiaridade com os termos científicos, apesar de demonstrarem não saber seu significado. Isso fica evidenciado na afirmação por meio de orações interrogativas: "É uma doença contagiosa, né? porque é uma doença que se espalha, né? por este mundo todo, né? É muito perigosa” (Morador B).

Os moradores exibem muitas dúvidas conceituais com relação à doença como é demonstrado na frase a seguir: "A dengue é um mosquito. A dengue é uma larva" (Morador C). Talvez isso resulte da mas- 
siva informação que circula, sem a preocupação com o entendimento que têm dos termos, então, eles repetem confusamente. E, às vezes, com alguma precisão, mas sem entender.

O mosquito é visto como uma ameaça e o causador intencional da doença: "Quando ele sai do vasilhame, ele já está pronto para voar e atacar qualquer um” (Morador F). Demonstram, assim, certo desconhecimento do ciclo de vida do mosquito e das condições e disseminação da infecção viral, de modo que o mosquito é visto como o principal causador da doença, reafirmando um modelo explicativo da doença de natureza unicausal.

Com relação à causalidade da doença, a oratória dos moradores é permeada pelo discurso da culpabilização, quando mencionam que o problema da dengue é do "povo": "Na verdade, eu acho assim. Se o foco da dengue aumenta, é culpa do próprio povo, que não procura preservar suas águas, manter tampada. Jogam cocos à toa" (Morador O).

Para a comunidade a presença do mosquito está relacionada à condição imprópria de moradia, devido à ausência de saneamento básico e coleta de lixo, que são responsabilidades do poder público: "Uma valeta, mas não adianta, é um minador que tem na rua ali. E aí ficam ali ó! O acúmulo de água! E a gente tem que ficar sempre escoando, quer dizer, eu já tentei com a prefeitura pra ver se a gente consegue pôr manilha de cobre, porque tem criança na rua. Tem várias crianças" (Morador B).

Os moradores trazem como práticas de prevenção a importância da educação, por meio da mídia, e a necessidade de adesão coletiva. Apenas, neste grupo, aparece a afirmativa de que a prevenção é de responsabilidade do poder público, e que suas ações de controle não têm sido suficientes: "Eu acho que o governo deve se preocupar com saneamento básico, é obrigação deles cuidar do saneamento básico, agora ele, o governo, ainda pela população é incentivo mesmo educativo, né?! Porque ele não pode entrar na residência de ninguém e ir fazendo a limpeza, não é?! Então, e eu acho que o governo já faz através da mídia. Todo mundo tem uma televisão em casa, né?! É! Eu acho que eles já fazem esse papel, mas a nível de saneamento básico tá faltando, ainda tá precisando mais" (Morador C).

Por fim, percebem a necessidade da adesão dos vizinhos, da coletividade às recomendações de prevenção: "Então temos que ter cuidado, porque se não tiver cuidado... Porque não adianta eu tapar a minha vasilha aqui, e a do vizinho estar aberta. Porque, pelo cheiro da gente, ele vai longe" (Morador F).

\section{Saberes e práticas dos ACEs de campo}

Os ACE de campo aparentam estar em conflito entre os saberes que possuem e outros que não dominam, mas que reconhecem como necessários para informar a comunidade. A partir das entrevistas, foi possível perceber que não há domínio do conhecimento técnico-científico sobre dengue, aproximando os seus saberes ao conhecimento do senso comum. Os ACE consideram que precisam ter apropriação de informações mais precisas para passar ao morador. A ausência desse conhecimento traz desconforto para efetividade do trabalho educativo: "Como é que a gente pode passar para o morador se a gente não tem uma formação de como é” (ACE campo A). Isso se traduz em dificuldades de comunicação com os moradores, pois esses se utilizam de conceitos preestabelecidos, que o agente não é capaz de desconstruir ou dialogar com eles.

Os ACE relataram que obtêm muitas notícias informalmente, mediante conversas com os colegas no trabalho de campo e moradores. Recorrem, por vezes, a "ditos populares" durante sua conversa com os moradores: "Tem um dito popular também que o mosquito tem um período que ele gosta mais de voar, que o indice de contato com o inseto é maior, que é diário, o contato diário e tal..." (ACE campo B).

Com relação à causalidade da dengue, esses agentes identificam a ignorância dos moradores como um dos principais fatores. Pois, na visão dos ACE de campo, a causa da dengue está associada à ausência de educação e conhecimento dos moradores. Entretanto, a despeito da afirmativa de que lhes carecem informações precisas sobre a dengue, os ACE que residem na comunidade em que trabalham apresentam um discurso de que não agem como os moradores, pois estão revestidos de um saber diferenciado em relação à população local. Essa situação também evidencia o conflito em que vivem, pois, do lugar profissional que ocupam, é esperado que, de fato, se diferenciem e sejam capazes de contribuir para uma compreensão mais aprofundada do problema da dengue.

Assim como os moradores, responsabilizam o poder público pela falta de infraestrutura da cidade, as más condições de moradia da população. Destacam as diversas dificuldades de acesso aos imóveis, o que inviabiliza, em parte, a realização de seu trabalho: "Tem muito terreno que são terrenos baldios e muitos 
terrenos baldios eles acumulam muito lixo. Às vezes, a gente tem dificuldade de acessar esses lugares porque crescem e tem muito mato, então, a gente não tem condição de adentrar para ver, e aí, quando a gente adentra, que a gente vê que tem muito copo focado, tem muito vasilhame que está focado" (ACE campo B).

O grupo se sente desvalorizado como agente educador e como seres humanos, atribuindo, como uma das causa da dengue, o mau desempenho do seu trabalho de campo, vinculado ao descaso do poder público para com eles, pela ausência de atividades regulares de valorização e capacitação, baixos salários e perseguições internas: “...por conta da falta de valorização, porque uma pessoa mal capacitada, uma pessoa mal valorizada, ela não é a mesma. Você tá trabalhando não obrigado praticamente, mas você tá trabalhando porque você precisa. Só que vai estar ali na sua mente que você está sendo mal pago, que você está enfrentando perseguições e uma série de coisas. Então, isso influencia um pouco nesse fator" (ACE campo A).

Os ACE destacaram a educação como prática prioritária de prevenção no combate à dengue. Enfatizaram a educação infantil, pois, na visão deles, as crianças são boas disseminadoras de ideias: "É aquela questão que você falou, para ensinar a criança, é muito difícil, mas ensinar o adulto é pior ainda, então, tem que vir mais das escolas, né? Porque as crianças vão servir como um multiplicador de informação, né?" (ACE campo D).

Apenas os ACE de campo relatam insatisfação com o trabalho, especialmente no que se refere ao acesso ao resultado de seus esforços. Segundo eles, há coleta constante de dados e total falta de feedback por parte da coordenação do programa sobre os resultados do trabalho de campo: "É. A gente coleta $o$ foco, vai para o laboratório, e, às vezes, o morador nem fica sabendo se o foco era positivo ou negativo. Ele quer saber o resultado, e a gente não tem" (ACE campo G). Situação que gera dúvidas sobre a validade do esforço: "...Mas, quando a gente termina o LIRAa, quando eles fazem a análise e tudo. O indice nunca chega para a gente, para a gente saber se o nosso trabalho está sendo eficaz ou não. Não tem resposta” (ACE campo E). Além disso, eles não se sentem devidamente informados sobre o local de atuação da atividade, afirmando que a coordenação define a área de trabalho sem explicação, sem diálogo. Consideram que há maior preocupação por parte da gestão com a produtividade do que com a qualidade do serviço.

Durante as entrevistas, percebe-se a consciência do agente em relação ao abandono institucional por parte do Estado, pela ausência de políticas públicas, capacitação dos serviços, fragmentação das ações ao que eles parecem resistir: "Agora se a gente desistir, eu nunca vou ver acontecer, então a gente tem que ficar sempre lutando, e por isso que a gente precisa ser mais valorizado, ser mais capacitado. E não está investindo no momento, tá entendendo? Porque há um descaso em relação, dos governantes, que nunca se importaram muito com a gente, com nada, eles só queriam ver os agentes como a válvula de escape..." (ACE campo A). Os agentes precisam ainda lidar diariamente com as condições sanitárias precárias do bairro como falta de coleta de lixo, esgotamento sanitário inadequado, ausência de pavimentações, presença constante de reservatório de água nas casas devido ao fornecimento irregular.

\section{Saberes e práticas dos ACE de mobilização}

Os ACE de mobilização demonstram maior familiaridade com palavras de cunho científico e facilidade em se expressar, não utilizando muitos termos do senso comum. Afirmam que seu conhecimento foi adquirido em palestras educativas, contudo, percebe-se que sua retórica pode ser confusa pelo uso incorreto dos conceitos sobre a doença: "São quatro tempos, que são duas clássicas, a hemorrágica e a tipo quatro que ainda eu não sei definir muito, que é o tipo quatro...” (ACE mobilização C).

Com relação à causalidade da dengue, identificam a falta de preparo dos médicos e da população. Na visão dos ACE de mobilização, parte da causa do elevado número de óbitos por dengue é o despreparo das equipes médicas em identificar os casos graves da doença. Além disso, pelo maior contato com a população, enfatizam a falta de conscientização e percepção do morador acerca do ambiente que o rodeia, e sua ausência de responsabilidade pelas condições do seu próprio imóvel: " $E$ ele me culpou o irmão, ela me culpou a irmã, ela me culpou o pedreiro que estava lá. Ela me culpou outra pessoa, mas ela não se culpou... Eu tenho certeza que eu vou voltar, e o muro dela vai estar focado. Porque ela simplesmente não admite que ela tem culpa daquela situação..." (ACE mobilização A).

Para esse grupo, a ênfase da prevenção recai sobre o compromisso individual do ACE de mobilização, trazendo um discurso individualista, no qual o principal sujeito da ação de prevenção é o "Eu" para o controle da dengue. Devido à necessidade de realizar suas ações educativas sem apoio 
institucional, eles criam, de forma autônoma, suas próprias condições de trabalho por meio de colaborações obtidas na comunidade.

Os ACE de mobilização fazem críticas à ausência de ações do governo e aos erros associados às campanhas televisivas, que, segundo eles, não trazem qualquer consequência prática para a solução dos problemas associados à dengue: “Assim, em relação ao que ela falou das políticas públicas e dos meios de comunicação, acho fraquíssimo. Eu vejo que precisa do apoio dos principais meios de comunicação. E quando se coloca uma propaganda televisiva como essa que está acontecendo, por exemplo, mosquito, Red Bull... A gente vai nas escolas e fala para os alunos que o mosquito tem característica preta e branca. Então, vão lá e joga um mosquito marrom com listagem tipo creme, caramelo etc. Então, o aluno te pergunta: por que você falou que ele era preto e branco, mas lá tá assim? Porque criança a gente tá construindo uma formação. Então, nossos meios de comunicação vão lá e desconstroem aquilo que a gente disse aos meninos de 7 e 8 anos" (ACE mobilização J).

O grupo indica o processo de educação e conscientização como prática ideal para enfrentar o problema. Eles têm a percepção de que a educação pode ser um processo lento e de difícil avaliação: "É educação. Todo processo de educação é lento. De qualquer tipo, a própria educação escolar que diferencia-se pela sua referência. Então, eu tenho um trabalho lá, na biblioteca. A gente sua com os meninos para querer ler, sua com os professores para valorizarem isso. Mas uma educação patrimonial, e esse processo não pode parar o processo de educação" (ACE mobilização J).

\section{Saberes e práticas dos ACSs}

Os ACS demonstram maior facilidade de se comunicar que os ACE, apesar de apresentarem os mesmos usos incorretos de conceitos sobre a dengue que os outros agentes: "E apesar de muitos não se darem conta, é mais perigosa do que muitos pensam, tanto é que se pode levar até à morte. É uma doença, ela tem sintomas de virose. Ela pode ser confundida com a virose, com a rubéola, e também... Com a virose e com a rubéola que têm os sintomas parecidos” (ACS E).

A linguagem dos ACS se diferencia dos ACE de campo e mobilização pois não utilizam os mesmos jargões ou termos científicos comumente utilizados por esses, aproximando-se mais da linguagem coloquial dos moradores: "Ela é causada por um mosquito que é preto com as perninhas pintadinhas de branco. E, a picada que ela pode pegar a doença da dengue é pela fêmea" (ACS G). Eles demonstram certo desconhecimento sobre o controle vetorial, sem apresentar desejo de adquiri-lo. Também não apresentam conflito pela falta de conhecimento específico para se comunicar com os moradores.

Esse grupo não demonstra apropriação de conhecimento específico sobre o vetor ou causas da dengue, detendo-se na visão das condições gerais de saneamento que propiciam a multiplicação do vetor: "Os dois. Vocês acham que é o mosquito? Algumas pessoas acham que é o lixo" (ACS G). Talvez ignorem seu papel de disseminadores de informações sobre a dengue para população e não tenham sido capacitados para tal responsabilidade. Dessa forma, direcionam o enfoque de culpabilização dos moradores: "Justamente, como a minha colega falou, aparece justamente pela falta de cuidado" (ACS A).

Quanto às práticas de prevenção, os ACSs são da mesma opinião dos ACES, apoiando a educação como forma de prevenção: "Educação é priori para mim. Vocês podem até discordar, mas se houvesse educação no geral, eu acho que diminuiria muito" (ACS A).

\section{Discussão}

Não há dúvidas quanto à complexidade do problema da dengue e suas formas de prevenção e controle. A despeito disso, educar a população continua a ser o maior desafio do governo para enfrentar o problema. Há também a complexidade de processos educativos a qual aponta que a educação em saúde não deve ser pensada de forma unidirecional, como transmissão/difusão de conhecimentos e informações entre um emissor e um receptor, tal como é, muitas vezes, praticada em serviços de saúde 26. Por sua vez, a mobilização social em saúde só pode proporcionar um ganho à educação pelo envolvimento da população no processo de construção e significação social dos conceitos, atitudes e práticas para controle da dengue. 
Dentro dos grupos trabalhados neste estudo, os moradores percebem que a problemática da dengue está associada a diversos fatores incluindo a participação da comunidade. Essa percepção pode demonstrar um avanço na promoção de qualidade de vida e redução da vulnerabilidade relacionada aos seus determinantes e condicionantes, se isso se reverter em ação transformadora do grupo social afetado. Contudo, embora alcançar a consciência da comunidade de sua própria responsabilidade seja um dos enfoques para a promoção da saúde 27 , corre-se o risco de que a ênfase da promoção recaia na responsabilização da população, em detrimento de medidas que modifiquem as condições socioambientais favoráveis à reprodução do mosquito. De sua parte, os moradores reconhecem seu nível de responsabilidade pelo controle vetorial e, frequentemente, atuam, de certo modo, reproduzindo a lógica da culpabilização, quando responsabilizam o "outro", em geral, o vizinho, pelas dificuldades enfrentadas do controle.

Passos et al. 28 já haviam demonstrado que a participação comunitária tem um papel relevante no controle vetorial. Seu estudo relata que atividades de combate às larvas de A. aegypti, baseadas em participação popular, levam a mudanças comportamentais da comunidade em relação ao cuidado com criadouros potenciais. Quando existe uma atuação conjunta entre população e instituições no planejamento de atividades educativas para controle e prevenção da dengue, os méritos são indiscutíveis. França et al. 29 demonstrou êxito na implantação de uma nova proposta de combate à dengue por meio da participação dos moradores na identificação de problemas no bairro e na elaboração das propostas de solução, com resposta satisfatória dos serviços públicos. A promoção da saúde requer que a produção de conhecimento e das práticas se faça por meio da construção de saberes e da gestão compartilhada por meio de mobilização e participação social 27.

Todavia, as informações circulantes perdem seu significado quando contradizem as condições socioambientais existentes na comunidade, como, por exemplo, a mensagem: "não deixe água parada", em locais onde há intermitência no abastecimento de água 26 . Essa dissintonia entre discurso e prática é agravada pela pobreza nos bairros trabalhados. Como consequência, as condições sociais repercutem de forma decisiva sobre a dinâmica do bairro, sobretudo na falta de intervenções urbanas que precisariam ser realizadas de forma contínua e sistemática 30 . É notório que moradias inadequadas e ausência de saneamento básico culminam no aumento da incidência de arboviroses transmitidas pelo A. aegypti 7,31, sendo necessário implementar estratégias de controle vetorial adaptadas à realidade local. Ademais, associações reivindicam das autoridades competentes a imediata revisão do modelo de controle vetorial e questionam ausência de prioridades na realização de ações de atenção à saúde do cidadão 32 .

Os ACE de campo demonstram consciência de seu conhecimento limitado sobre a dengue, fator essencial para o diálogo e interatividade no processo de significação social, e apresentam um discurso de indignação devido ao descaso do governo para sua qualificação. Corrobora com a análise de perfil dos ACE, realizada por outro trabalho por meio da técnica de GF, que mostra que os agentes devem ser devidamente capacitados para exercerem seu papel de educadores com qualidade e eficiência 33. Desse modo, não há como o agente dialogar e aprimorar a compreensão do morador sobre a necessidade de melhorias, mesmo diante de condições adversas em seu ambiente. Pois, para modificar o comportamento, é necessário que o morador entenda o contexto no qual ocorrem os significados, e a importância a ele atribuídos pelos agentes, e encontre condições adequadas para a realização de novas práticas. Assim, os indivíduos poderiam construir o conhecimento num processo dinâmico de trocas e construção de saberes e experiências 26,34.

Os ACE de mobilização evidenciam o discurso de culpabilização da população, considerando que essa resiste em se apropriar dos conhecimentos transmitidos. Entretanto, essa "resistência" pode ser vista associada à desigualdade social, econômica e ambiental, que, ao colocar os sujeitos em situação de vulnerabilidade social, define também um outro lugar de atribuição de sentidos para a doença. Esse discurso traz a concepção individualizante que atribui ao sujeito a culpa por seus insucessos 35 , responsabilizando-o por eles. Tal discurso tem sido tão difundido quanto criticado no campo da saúde. Para Castiel \& Álvarez-Dardet 36 (p. 35), "a ideia de culpa envolve, antes de tudo, um julgamento e a desaprovação de alguém em função de alguma falha, transgressão em relação à moral ou às leis vigentes em um determinado contexto". Configura-se como "um poderoso fator de ordem social que normatiza e procura viabilizar o convívio humano", e sua ameaça "pode ser constrangedora para a maioria das pessoas..." Na medida em que os ACS culpabilizam a população, introduzem certamente um elemento que dificulta o processo 
educativo que deveriam realizar, que estaria próximo ao conceito de educação difusa 37,38, ou seja, aquela que "transcende o contexto escolar e se encaixa nas relações sociais cotidianas, voltadas à transmissão de comportamentos, disposições, crenças e competências" 37 (p. 863).

Na perspectiva ampliada de saúde, os modos de viver individual e comunitário estão associados também à ordem coletiva, uma vez que seu processo de construção se dá no contexto da própria vida, descontruindo a visão tradicional de trazer o sujeito como o único responsável pelas diversas mudanças ocorridas no processo saúde-adoecimento ao longo da vida 27.

Uma situação peculiar surge em relação aos ACS, que não parecem preocupados com a situação real da doença frente à comunidade. Diferente dos ACE, os ACS não apropriaram sua experiência de campo em seu discurso. Eles parecem ignorar o fato de que são disseminadores de informações para a população, não se sentindo responsáveis pela problematização da dengue. Isso pode ser explicado pelo fato de que o papel dos ACS atualmente encontra-se distorcido, as ações desenvolvidas por esses profissionais estão voltadas para diferentes grupos populacionais, com ênfase na nutrição, planejamento familiar, sensibilização da comunidade aos direitos humanos, dentre outras. Assim, qualquer ação que deva ser desenvolvida nas famílias e na comunidade é atribuída a eles, isso esbarra diretamente na falta de qualificação 14,39 .

Por meio dos discursos dos moradores e agentes durante as entrevistas, foi possível perceber que, na metodologia atual, a disseminação de informação e conhecimento não é suficiente para promover melhorias na comunidade para o controle da dengue. Em parte, percebe-se que os agentes lidam com essas percepções no seu dia a dia.

Para que haja um melhor direcionamento das ações de mobilização social e educação em saúde, é necessário aproximar-se, de modo compreensivo, dos conhecimentos, atitudes e práticas da população em relação à dengue, pois o conhecimento prévio de como a população pensa e age é fundamental para estabelecer o diálogo e a sensibilização necessários ao processo educativo. Entre os desafios da educação em saúde, está a criação e o aperfeiçoamento de técnicas de intervenções regulares de qualificação dos agentes para práticas de educação e comunicação, pautadas no diálogo e na sensibilização para lidar com a realidade cotidiana dos moradores; proporcionar-lhes maior participação dentro de um quadro atualizado de informações oficiais sobre as doenças, assim como inseri-los nas tomadas de decisões com base no contexto de campo, vivenciado por esses atores no processo de controle vetorial 40,41.

Concluindo, a estratégia do GF possibilitou perceber as necessidades e demandas tanto da comunidade quanto dos ACE e ACS, dentro do contexto das práticas de controle da dengue. Corroborando com outros autores, foi possível perceber que a melhor perspectiva para um controle vetorial de combate à dengue mais eficiente é o investimento em educação dialógica e multirreferencial, com participação social, trazendo os indivíduos (moradores e agentes) como sujeitos do processo de construção de conhecimento 12,33,42. Entretanto, há que se destacar que a educação em saúde não é uma panaceia para os males da saúde pública, especialmente aqueles que decorrem das condições de infraestrutura das cidades e demanda sua melhoria. 


\section{Colaboradores}

K. R. Souza, M. L. R. Santos e L. K. Silva contribuíram com a concepção do projeto; execução, análise e interpretação dos dados; redação do artigo e revisão crítica relevante do conteúdo intelectual; e aprovação final da versão a ser publicada. I. C. S. Guimarães e G. S. Ribeiro contribuíram com a concepção do projeto; revisão crítica relevante do conteúdo intelectual; análise e interpretação dos dados; e aprovação final da versão a ser publicada.

\section{Agradecimentos}

Agradecemos aos moradores, agentes de combate às endemias (ACE) de campo e de mobilização, e agentes comunitários de saúde (ACS) de Periperi e Plataforma que participaram deste estudo; ao Grupo de Valorização dos ACE (GDVAE) pela interlocução e programação dos trabalhos juntos com os ACE; e à diretora-geral de vigilância à saúde, na pessoa da Dra. Geruza Maria Moraes Cunha, pela colaboração em todas as etapas do trabalho e pela liberação dos ACE para participar da pesquisa. Fundação de Amparo à Pesquisa do Estado da Bahia (FAPESB; Edital de Apoio à Articulação Pesquisa e Extensão no 029/2012).

\section{Referências}

1. Campos GS, Bandeira AC, Sardi SI. Zika virus outbreak, Bahia, Brazil. Emerg Infect Dis 2015; 21:1885-6.

2. Cardoso CW, Paploski IA, Kikuti M, Rodrigues MS, Silva MM, Campos GS, et al. Outbreak of exanthematous illness associated with Zika, Chikungunya, and Dengue viruses, Salvador, Brazil. Emerg Infect Dis 2015; 21:2274-6.

3. Teixeira MG, Andrade AM, Costa MC, Castro JN, Oliveira FL, Goes CS, et al. East/Central/ South African genotype chikungunya virus, Brazil, 2014. Emerg Infect Dis 2015; 21:906-7.

4. Huber K, Loan LL, Chantha N, Failloux AB. Human transportation influences Aedes aegypti gene flow in Southeast Asia. Acta Trop 2004; 90:23-9.

5. Tauil PL. Urbanização e ecologia do dengue. Cad Saúde Pública 2001; 17 Suppl:99-102.

6. Teixeira MG, Costa MCN, Barreto F, Barreto ML. Dengue: twenty-five years since reemergence in Brazil. Cad Saúde Pública 2009; 25 Suppl 1:S7-18.

7. Zellweger RM, Cano J, Mangeas M, Taglioni F, Mercier A, Despinoy M, et al. Socioeconomic and environmental determinants of dengue transmission in an urban setting: an ecological study in Nouméa, New Caledonia. PLoS Negl Trop Dis 2017; 11:e0005471.

8. Secretaria de Vigilância em Saúde, Ministério da Saúde. Resultado do LIRAa Nacional de 2016. Brasília: Ministério da Saúde; 2016.

9. Secretaria de Vigilância em Saúde, Ministério da Saúde. Monitoramento dos casos de dengue, febre de chikungunya e febre pelo vírus Zika até a Semana Epidemiológica 19, 2017. Bol Epidemiol 2017; 48:1-10.

10. Martín JLS, Brathwaite O, Zambrano B, Solórzano JO. The epidemiology of dengue in the Americas over the last three decades: a worrisome reality. Am J Trop Med Hyg 2010; 82:128-35

11. Fundação Nacional de Saúde. Programa Nacional de Controle da Dengue (PNCD): instituído em 24 de julho de 2002. Brasília: Ministério da Saúde; 2002.

12. Baglini V, Favaro EA, Ferreira AC, Chiaravalloti Neto F, Mondini A, Dibo MR, et al. Atividades de controle do dengue na visão de seus agentes e da população atendida, São José do Rio Preto, São Paulo, Brasil. Cad Saúde Pública 2005; 21:1142-52.

13. Secretaria de Vigilância em Saúde, Ministério da Saúde. Diretrizes nacionais para prevenção e controle de epidemias de dengue. Brasília: Ministério da Saúde; 2009. (Série A. Normas e Manuais Técnicos).

14. Tomaz JBC. O agente comunitário de saúde não deve ser um "super-herói”. Interface Comun Saúde Educ 2002; 6:75-94.

15. Secretaria Executiva, Ministério da Saúde. Programa Agentes Comunitários de Saúde (PACS). Brasília: Ministério da Saúde; 2001. 
16. Ministério da Saúde. O trabalho do agente comunitário de saúde. Brasília: Ministério da Saúde; 2009.

17. Pinto AAM, Fracolli LA. O trabalho do agente comunitário de saúde na perspectiva da promoção da saúde: considerações práxicas. Rev Eletrônica Enferm 2010; 12:766-9.

18. Raymond M, Rousett F. GENEPOP (version 1.2): population genetics software for exact tests and ecumenicism. J Heredity 1995; 86:248-9.

19. Casal AY. Para uma epistemologia do discurso e da prática antropológica. Lisboa: Cosmos; 1996.

20. Fujita MS, Cervantes BMN. Abordagem cognitiva do protocolo verbal na confirmação de termos para a construção de linguagem documentaria em inteligência competitiva. In: Valentim MLP, organizador. Métodos qualitativos de pesquisa em ciência da informação. São Paulo: Polis; 2005. p. 29-58.

21. Boccato VRC, Ferreira EM. Estudo comparativo entre grupo focal e o protocolo verbal em grupo de aprimoramento de vocabulário controlado em fisioterapia: uma proposta metodológica qualitativa-cognitiva. InCID: Revista de Ciência da Informação e Documentação 2014; 5:47-68.

22. Cazola L, Pontes E, Tamaki E, Andrade S, Reis C. O controle da dengue em duas áreas urbanas do Brasil central: percepção dos moradores. Saúde Soc 2011; 20:786-96.

23. Soares AMC. Cidade revelada: pobreza urbana em Salvador-BA. GEOgrafias 2009; 5:83-96.

24. Dias CA. Grupo focal: técnica de coleta de dados em pesquisas qualitativas. Informação \& Sociedade: Estudos 2000; 10:141-58.

25. Guizzo BS, Krziminski CO, Oliveira DLLC. O software QSR Nvivo 2.0 na análise qualitativa de dados: ferramenta para a pesquisa em ciências humanas e da saúde. Rev Gaúcha Enferm 2003; 24:53-60.

26. Rangel-S ML. Dengue: educação, comunicação e mobilização na perspectiva do controle propostas inovadoras. Interface Comun Saúde Educ 2008; 12:433-41.

27. Ministério da Saúde. Política Nacional de Promoção da Saúde. Brasília: Editora MS; 2010.

28. Passos ADC, Rodrigues EMS, Dal-Fabbro AL. Dengue control in Ribeirão Preto, São Paulo, Brazil. Cad Saúde Pública 1998; 14 Suppl 2:123-8.

29. França E, de Paula JC, Silva RR, Anunciação LR. Participação da população em projeto de controle de dengue em Belo Horizonte, Minas Gerais: uma avaliação. Inf Epidemiol SUS 2002; 11:205-13.

30. Regis ISR. Lobato e Paripe no contexto da avenida suburbana: uma análise socioespacial [Dissertação de Mestrado]. Salvador: Instituto de Geociências, Universidade Federal da Bahia; 2007.
31. Spiegel JM, Bonet M, Ibarra AM, Pagliccia N, Ouellette V, Yassi A. Social and environmental determinants of Aedes aegypti infestation in Central Havana: results of a case-control study nested in an integrated dengue surveillance programme in Cuba. Trop Med Int Health 2007; 12:503-10.

32. Reis V. Cidades sustentáveis e saudáveis: microcefalia, perigos do controle químico e o desafio do saneamento universal. https://www. abrasco.org.br/site/2016/02/carta-de-alertada-abrasco-cidades-saudaveis-e-sustentaveis -este-e-o-desafio-urgente/ (acessado em 16/ Ago/2017).

33. Oliveira GLA, Nery CR, Diniz MCP, Schall VT. Prevenção e controle da dengue na visão de agentes de controle de endemias - desafios e perspectivas. In: II Congresso Online - Gestão, Educação e Promoção da Saúde. http://www.convibra.com.br/upload/ paper/2013/58/2013_58_7768.pdf.

34. Pessoa JPM, Oliveira ESF, Teixeira RAG, Lemos CLS, Barros NF. Control of dengue: consensus views of endemic disease control agents and community health agents on their integrated action. Ciênc Saúde Coletiva 2016; 21:2329-38

35. Pereira V, Guareschi P. Representações sociais da psicologia sobre os usuários do CRAS: culpabilização dos sujeitos em situação de vulnerabilidade social. Diálogo 2014; 26:9-24.

36. Castiel LD, Álvarez-Dardet C. A saúde persecutória: os limites da responsabilidade. Rio de Janeiro: Editora Fiocruz; 2007.

37. Barros AT. Educação e legislação: desafios para o aprendizado político e a cultura democrática. Educação \& Sociedade 2016; 37:861-72.

38. Petitat A. Educação difusa e relação social. Educação \& Realidade 2011; 36:365-76.

39. Wagner V, Oliveira LS, Polak R, Struwka S, Guimarães RS, Fujinaga CI. O grupo focal como estratégia de construção coletiva: relato de experiência com agentes comunitários de saúde de Irati/PR. In: Anais do XVIII Congresso Brasileiro de Fonoaudiologia. Exercício profissional: bases teóricas, avanço e realidade nacional. http://www.sbfa.org.br/portal/ anais2010/resumos/3199.pdf.

40. Souza VMM, Hoffmann JL, Freitas MM, Brant JL, Araújo WN. Avaliação do conhecimento, atitudes e práticas sobre dengue no Município de Pedro Canário, Estado do Espírito Santo, Brasil, 2009: um perfil ainda atual. Rev Pan-Amazônica Saúde 2012; 3:37-43.

41. Cavalcante KRJL, Porto VT, Taui PL. Avaliação dos conhecimentos, atitudes e práticas em relação à prevenção de dengue na população de São Sebastião - DF. Brasil, 2006. Comun Ciênc Saúde 2007; 18:141-6.

42. Sales FM. Ações de educação em saúde para prevenção e controle da dengue: um estudo em Icaraí, Caucaia, Ceará. Ciênc Saúde Coletiva 2008; 13:175-84. 


\section{Abstract}

Due to the persistence of dengue and other arbovirus infections in Brazil, the government has stepped up measures to combat the Aedes aegypti mosquito vector. The responsibilities of community endemic disease workers (CEDW) and community health workers (CHW) include acting as intermediaries and disseminating knowledge in the community. The aim of this study was to analyze knowledge and practices in dengue control by different social subjects: residents and CEDW/ $C H W$. Interviews were held with residents, field and mobilization CEDW, and CHW in two neighborhoods in Salvador, Bahia State, using focus groups. Residents expressed uncertainty on the form of transmission and hazards of dengue. Field $C E D W$ voiced conflicting feelings due to the need to inform the community on issues over which they lack any control, while expressing personal dissatisfaction with their work and a feeling of underappreciation due to their lack of training. Mobilization CEDW blamed the population and emphasized their own importance as the solution to dengue control. CHW failed to reflect their field experience in their discourse and felt they had no responsibility over vector control. All the groups agreed that government is to blame for dengue and that the solution lies in education. There is an evident need for regular educational interventions, based on dialogue and awareness-raising to deal with residents' daily reality, drawing individuals (residents and $\mathrm{CHW}$ ) into the knowledge-building process. Under the prevailing methodology, the dissemination of information and knowledge is insufficient to promote community improvements for dengue control.

Health Knowledge, Attitudes, Practice; Communicable Disease Control; Dengue

\section{Resumen}

Debido a la persistencia del dengue y de otras arbovirosis en Brasil, el poder público ha intensificado las acciones de combate al mosquito vector Aedes aegypti. Los ACE (agentes de combate a endemias) y los ACS (agentes comunitarios de salud), entre otras atribuciones, se convirtieron en interlocutores y promotores de conocimiento sobre enfermedades en sus comunidades. El objetivo de este trabajo fue analizar los conocimientos y prácticas sobre el control del dengue por parte de los diferentes sujetos sociales implicados: residentes $y$ agentes. Se realizaron entrevistas a residentes, ACE de campo y de movilización, así como ACS, en dos barrios de Salvador, Bahía, mediante una metodología de grupo focal. Los residentes mostraron inseguridad sobre la forma de contagio, así como el peligro que supone el dengue. Los ACE de campo se encontraron en conflicto, por su necesidad de informar a la comunidad sobre aspectos que no dominan, además de demostrar un descontento personal en el trabajo, unido a un sentimiento de desvalorización, por su falta de cualificación. Los ACE de movilización culpan a la población $y$ enfatizan la importancia de ellos mismos como solución para el control del dengue. Los ACS no se apropiaron de su experiencia de campo en su discurso y no se sienten obligados al control vectorial. Todos los grupos entrevistados concuerdan en que la culpa del dengue recae sobre el poder público, y la solución para el problema está en la educación. Se percibe una gran necesidad de intervenciones educativas regulares, pautadas en el diálogo y en la sensibilización para lidiar con la realidad cotidiana de los residentes, considerando a los individuos (residentes y agentes) como sujetos del proceso de construcción del conocimiento. Así pues, en la metodología actual, la divulgación de información y conocimiento no es suficiente para promover mejoras en las comunidades, con el fin de controlar el dengue.

Conocimientos, Actitudes y Práctica en Salud;

Control de Enfermedades Transmisibles; Dengue

Recebido em 07/Mai/2017

Versão final reapresentada em 13/Nov/2017

Aprovado em 21/Nov/2017 